\title{
List of contributors
}

David Blagden is Senior Lecturer in the Strategy and Security Institute, Department of Politics, University of Exeter.

Elena Chebankova is Research Fellow in the Centre for Government and Public Management, Carleton University.

H. D. P. Envall is Fellow in the Department of International Relations, Coral Bell School of Asia Pacific Affairs, Australian National University.

Ian Hall is Professor in the School of Government and International Relations, Griffith University.

James Johnson is Assistant Professor in the Department of Law and Government, Dublin City University.

Nicholas Khoo is Associate Professor in the Politics Programme, University of Otago.

Zhang Qingmin is Professor in the School of International Studies, Peking University.

Luis L. Schenoni is Postdoctoral Researcher in the Department of Politics and Public Administration, University of Konstanz.

Benjamin Zala is Research Fellow in the Department of International Relations, Coral Bell School of Asia Pacific Affairs, Australian National University. 